\title{
Structural Dynamic Study of Roof Waterproofing Materials
}

\author{
Alim Feizrakhmanovich Kemalov ${ }^{1}$, Ruslan Alimovich Kemalov ${ }^{1}$, Dinar Zinnurovich Valiev ${ }^{1} \&$ Ilmira \\ Maratovna Abdrafikova ${ }^{1}$ \\ ${ }^{1}$ Kazan (Volga region) Federal University, 8, Kremlevskaya Street, Kazan, 420008, Russian Federation \\ Correspondence: Alim Feizrakhmanovich Kemalov, Kazan (Volga region) Federal University, 8, Kremlyovskaya \\ Street, Kazan, 420008, Russian Federation. E-mail: Kemalov@mail.ru
}

Received: June 27, $2014 \quad$ Accepted: July 17, $2014 \quad$ Online Published: August 17, 2014

doi:10.5539/mas.v8n5p115 URL: http://dx.doi.org/10.5539/mas.v8n5p115

\begin{abstract}
The present research was aimed to develop the scientific applied principles and technologies of composite bituminous materials for civil engineering based on the investigation of the structures of polymer modifier and bitumen-polymer binder (BPB) on its basis with the use of nuclear magnetic resonance (NMR). The method of pulsed NMR was chosen as one of the rapid analysis methods that can be used for the analysis of bitumen-polymer systems, especially when assessing the group chemical composition of residual oil feedstock (ROF), bitumens and composite materials based on them. Using the method of pulsed NMR the regularities of the impact of modifier component composition on the changes of structural-group composition of the original and modified products were specified. Based on the results of research the optimal ratio of bitumen-polymer binder components was investigated, the manufacturability of the process for obtaining of composite bituminous materials for civil engineering with the aim of optimizing the quality of the final products was evaluated. Pulsed NMR - spectroscopy is suggested as input and output quality control of bituminous products. The regularities of redistribution of the phases with different molecular mobility and their relationship with the binder components were investigated. Rapid technique for quantifying the content of polymer in the solvent was developed.
\end{abstract}

Keywords: pulsed NMR, bitumen-polymer binder, structural-group composition, roof waterproofing materials, thermoplastic resins

\section{Introduction}

Nuclear magnetic relaxation (NMR) is one of the modern instrumental methods of physical chemistry (Kimmich and Anoardo, 2004; Conte and Alonzo, 2013, Xu et al., 2013, Bayer et al., 2013; Haber-Pohlmeier et al., 2013) and is a fundamental property of nuclear magnetism, characterizing the dynamics of nuclear spins system in the oil bitumen-polymer systems.

Pulsed NMR method increasingly finds its application in rapid analysis of the bitumen-polymer systems, especially when assessing the group chemical composition of residual oil feedstock (ROF), bitumens and composite materials based on them. It should be noted that the study of NMR spectra is based on the resonating nuclei systems that are extremely sensitive to the magnetic environment where the local magnetic fields near the resonating nuclei are dependent on the intra- and intermolecular effects. This determines the value of NMR spectroscopy to investigate the structure and behavior of many-electron (molecular) systems in different fields of science (Washburn and Birdwell, 2013; Nascimento, et al., 2004; Bayer, et al., 2010; Berman, et al., 2013; Charlier, et al., 2013; Kemalov, et al., 2012; Kemalov et al., 2013; Kruk et al., 2012, Twieg, 2013, Frantsuzov, 2010).

Thus, the method of pulsed NMR today attracts not only physicists and chemists, but also experts in the field of technology, which is primarily due to the practical significance of the NMR data, the processes of which depend on many physical and chemical properties of the system and illustrate the excellent dynamic phenomena at a molecular level.

The research of roofing waterproofing materials using NMR relaxometry primarily allows to study the effect of temperature on the structural and dynamic state of the oil disperse system (ODS) at the molecular level with a subsequent change of thermodynamic characteristics of the spin-spin components of the ODS. Thus the structural features of ODS in general can reliably be assumed (Kemalov and Kemalov, 2013).

Waterproofing materials that are related to ODS, are known for a long time and are used for different purposes: 
to protect roofs against the penetration of atmospheric precipitates (roofing), for waterproofing in the construction of underwater and above-water parts of dams and bridges (waterproofing). In order to reduce costs and extend the life of roofing materials by virtue of their physical nature and structural features the injection of specially selected polymer modifiers according to their chemical nature and reactivity in the operating conditions in the construction is conducted, resulting in a change in the structure and properties of organic binding materials Injection of a suitable polymer modifier gives cementing materials more heat and frost resisting, elasticity, increased resistance to fatigue, improves durability (Kemalov and Kemalov, 2013).

One of the most promising polymer materials used in civil construction at the bitumen of different brands modification with is the class of thermoplastic resins (TPR). Due to the fact that the injection of the chosen TPR into the bitumen (Russian standard - "technical terms" -TU 2451-089-05766801-99) in the solid state (with no use of solvent-plasticizer), there is hardening of the polymer-bitumen material, while the softening temperature increases (from 89 to $120^{\circ} \mathrm{C}$ ) because of the high structuring ability of TPR. This is the reason for the lack of the proper elasticity, frost resisting of roofing material. Therefore, at the modification of this raw material it is advantageous to inject the selected polymer either in the form of a polymer solution (polymer + plasticizer-solvent) or in a way of step-by-step injection of polymer and a plasticizer-solvent. In studies we used the plasticizer that is in a semi-drying oils class (SDOs) as a dissolving agent. Selected SDO (Russian State standard - GOST 8988-59) is characterized by the presence of large amounts of fatty acids and one double bond. According to the type of fatty acids contained in the glycerides, SDO are composed of saturates $-7,3-10 \%$, components with one double bond $-67,5-75 \%$ and several double bonds $-15-25,2 \%$ (Kemalov and Kemalov, 2013).

\section{Method}

While developing the scientific applied principles and technologies of composite bituminous materials for civil engineering the structures of polymer modifier and bitumen-polymer binder (BPB) on its basis were investigated by nuclear magnetic resonance (NMR).

This method belongs to the modern instrumental methods of research, which is based on a fundamental property of nuclear magnetism, characterizing the dynamics of nuclear spins in a dispersed system - polymer solutions, bitumen, bitumen-polymer binders and so on. Highly informative parameters of nuclear magnetic relaxation connected to the tested substance properties, the relative simplicity of the experimental determination of these parameters, as well as the reliability of the theoretical interpretation of the data allow to allocate it to the independent physical method of investigation.

For the analysis of polymer solutions of different concentrations using pulsed NMR, the following measurement modes were used: start-up period $\mathrm{T}=3000 \mathrm{~ms}-12 \mathrm{~s}$, the interval between $90^{\circ}$ and $180^{\circ}$ pulses $\mathrm{N}=100-2500$, the number of scans $n=10-30$ (for the spin-spin system ) and the start-up period $T=500 \mathrm{~ms}-2 \mathrm{~s}$, the interval between $90^{\circ}$ and $180^{\circ}$ pulses $\mathrm{N}=50-1000$, the number of scans $\mathrm{n}=10-30$ (for the spin-lattice system). Analysis time did not exceed 3 min.

Selecting the temperature range, at which the studies were conducted, was not accidental. In this temperature range of $20-140^{\circ} \mathrm{C}$ the major technological operations with oil bitumen are carried out.

The analysis of solutions of TPR in SDO was conducted at a temperature of $140{ }^{\circ} \mathrm{C}$ (the temperature of mixing). As seen from the graph (Figure 1) in the polymer solution at a predetermined temperature, the presence of three phases is observed. The phase with the longest time of relaxation will be specified as "a." The phase that has the shortest time of spin-spin relaxation is "c", and the phase having an intermediate value of relaxation time is denoted as "b". The values of spin-spin relaxation time for the lightest phase $T_{2 a}$ and the intermediate phase $T_{2 b}$ decrease with the increasing of polymer content in the solution. At the same time, the relaxation time of the heaviest phase is almost independent from the content of the TPR in solution. The dependence of the spin-spin relaxation time from the content of the TPR in solution is linear. Therefore, in general, its analytical expression have the form $\mathrm{y}=\mathrm{kx}+\mathrm{b}$, where $\mathrm{k}$ - is slope.

\section{Analysis and Results}

As a result of analysis of experimental data empirical dependence of the spin-spin relaxation time from the content of the TPR in the sample solution was obtained:

$$
\begin{aligned}
& \mathrm{T}_{2 \mathrm{a}}=-16.996 \mathrm{x}+1503.9(1) \\
& \mathrm{T}_{2 \mathrm{~b}}=-5.1158 \mathrm{x}+435.74(2) \\
& \mathrm{T}_{2 \mathrm{c}}=-0.7248 \mathrm{x}+64.572,(3)
\end{aligned}
$$


where $T_{2 a}$ is the spin-spin relaxation time of the "long-time" phase, $T_{2 b}-$ the spin-spin relaxation time of the intermediate phase, $\mathrm{T}_{2 \mathrm{c}}$ - the spin-spin relaxation time of "short-time" phase.

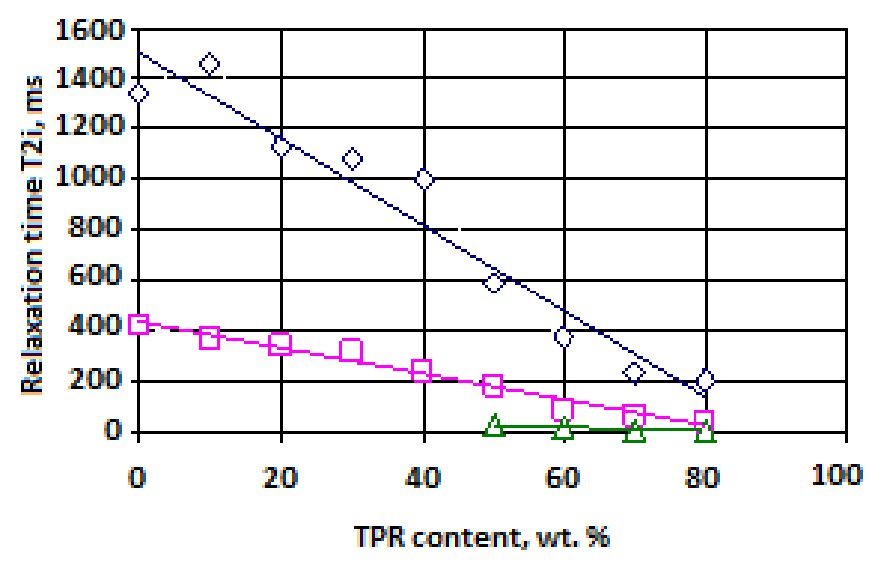

$$
-\diamond-\mathrm{T}_{2 \mathrm{a}},-\square-\mathrm{T}_{2 \mathrm{~B}},-\wedge-\mathrm{T}_{2 \mathrm{c}}
$$

Figure 1. The dependence of spin-spin relaxation $\mathrm{T}_{2 \mathrm{i}}$ from the content of TPR in the solution of $\mathrm{SDO}$ at $140{ }^{\circ} \mathrm{C}$

Analysis of the conducted NMR studies experimental data with pure solvent-plasticizer in the entire temperature range from 20 to $140{ }^{\circ} \mathrm{C}$, where the presence of two phases observed, allows suggesting that the presence of the third phase "c" is due to the presence of dissolved TPR. Thus, the phases "a" and " $b$ " characterize the components of the solvent, and the shortest by time phase "c" characterizes the dissolved polymer and some of the solvent that is associated with the polymer. Figure 1 shows that the injection of $10 \mathrm{wt} \%$ of TPR into SDO results a decrease of the spin-spin relaxation time values (from 1500 to 1350 and from 425 to 370 , respectively) of phases "a" and "b". As mentioned above, the preliminary analysis of the experimental data revealed that the phases "a" and "b" refer to a solvent. Reduction of spin-spin relaxation times of these phases in our view can be explained by the fact that some of the SDO molecules are included into the spatial structure of the polymer, and thus lose some of their mobility. From the nature of the slope (Figure 1), it can be assumed that the polymer has a greater effect on the phase "a", i.e. on the light part of the SDO.

\section{Discussion}

Decrease of the values of spin-spin relaxation $\mathrm{T}_{2 \mathrm{a}}$ and $\mathrm{T}_{2 \mathrm{~b}}$ with the increase of TPR content in SDO also indicates the decrease in the mobility of the system, which confirms the earlier made assumptions about the high structuring ability of TPR.

Figure 2 shows a graph of the proton phases population from the concentration of TPR in SDO.

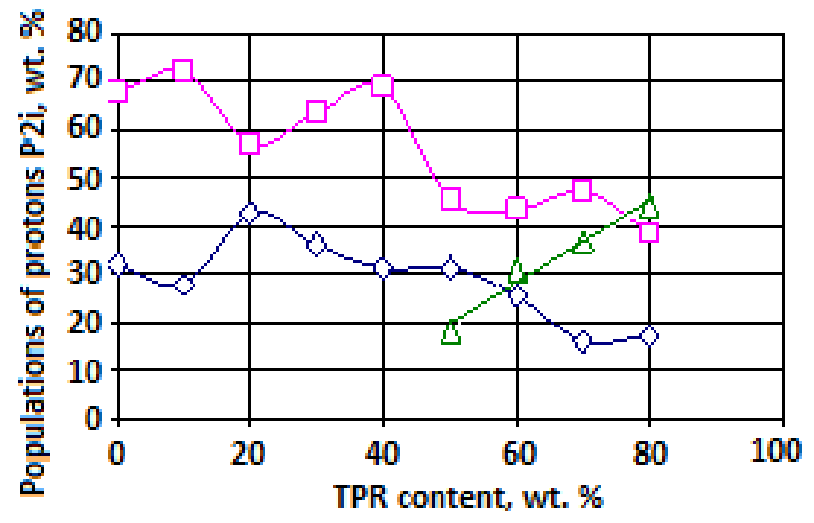

$$
-\diamond-\mathrm{T}_{2 \mathrm{a}},-\square-\mathrm{T}_{2 \mathrm{~B}},-\Lambda-\mathrm{T}_{2 \mathrm{c}}
$$

Figure 2. Dependence of the populations of protons in phases $\mathrm{P}_{2 \mathrm{i}}$ from TPR content in the solution of SDO at $140{ }^{\circ} \mathrm{C}$ 
Diagrams of $\mathrm{P}_{a}$ and $\mathrm{P}_{b}$ dependences have polynomial nature, while $\mathrm{P}_{c}$ dependence is linear. $\mathrm{P}_{\mathrm{a}}$ dependence curve has a maximum at the points corresponding to a polymer content of $10 \%$ and $40 \%$ by weight, and the minimum is at the points corresponding to the TPR concentration of $20 \%$ and $50 \%$ by weight. The initial increase in the TPR "long-time" phase $\left(\mathrm{P}_{2 \mathrm{a}}\right)$ content from $0 \%$ to $20 \%$ by weight can be explained by the decrease of molecular mobility due to their interaction with the polymer molecules. Thus molecules of this phase verge into a phase with a short relaxation times - phase "b". Probably some of these molecules lose mobility so much that moves into the phase with the shortest time of spin-spin relaxation, i.e. the phase "c". The further small-scale decrease in the phase "a" amount is likely caused by the increased content of phase "b", part of its molecules goes into "c"-phase, if the concentration of TPR is more than $50 \%$ by mass. The further reduction of the phase "a" population is probably due to the transition of the molecules of this phase into the phases "b" and "c". As previously mentioned, the dependence of $\mathrm{P}_{2 \mathrm{c}}$ from the content of TPR is linear. As a result of the mathematical analysis of the dependence the empirical expression relating the content of the TPR in the solution and the population of protons in phase "c":

$$
\mathrm{P}_{\mathrm{c}}=\mathrm{A} \cdot \mathrm{C}-\mathrm{B}(4)
$$

where $\mathrm{C}$ - the content of the TPR in solution of rapeseed oil, \% wt.; $\mathrm{P}_{\mathrm{c}}$ - population of protons in phase "c", \%; A and $\mathrm{B}$ - empirical coefficients: $\mathrm{A}=0.845, \mathrm{~B}=22.4$

Change in the group composition of bitumen after its modification plays an important role in the study of BPB. NMR method allows determining group composition of bitumen and BPB with an accuracy of $3 \%$, this will allow us to estimate the composition changes, as well as the convergence of the results obtained by other methods (Conte and Alonzo, 2013; Kimmich and Anoardo, 2004, Bayer et al., 2010).

The essence of the definition is as follows. Sample preparation procedure consisted of the analyzed substance to be placed in the tube and fixing it to the sensor unit. To carry out the NMR experiment investigated system (oil residue) is simultaneously placed in a constant magnetic field (MF) and a pairs of pulses of the MF with a variable time interval between pulses. At equilibrium nuclear magnetization is directed along the constant MF. Using a variable magnetic field, the magnetization can be deflected from the constant field direction, thereby moving the nuclear spin system in a controlled non-equilibrium state. Variable magnetic field should be directed perpendicularly to the constant MF, directed perpendicularly to the pulsed magnetic field and opposite to the pulses of pair. Then comes the registration of the magnetization projection of the analyzed bitumen sample on the direction of the constant magnetic field through a fixed time interval after exposure of each pair of magnetic field pulses. In order to increase the informativity of the mode, the initial value of the magnetization projection of the analyzed bitumen sample on the direction of the constant magnetic field is recorded beforehand, whereupon the measuring cycle is performed twice at a sample temperature of $40{ }^{\circ} \mathrm{C}$ and $100{ }^{\circ} \mathrm{C}$, respectively (Xu et al., 2013; Kruk et al., 2012; Haber-Pohlmeier et al., 2013). And after each measuring cycle the amplitude of the transverse magnetization of the analyzed sample is determined by extrapolating the linear part of the logarithm of the projection of the sample magnetization and the time interval between the pulses of the magnetic field onto zero time interval between the pulses and then the group content of oils, asphaltenes and resins is determined from the relations: $\mathrm{P}_{\mathrm{A}}=\mathrm{A}_{1} \cdot 100 / \mathrm{A}_{0} ; \mathrm{P}_{\mathrm{C}}=\left(\mathrm{A}_{0}-\mathrm{A}_{2}\right) \cdot 100 / \mathrm{A}_{0}, \mathrm{P}_{\mathrm{B}}=100-\mathrm{P}_{\mathrm{A}}-\mathrm{P}_{\mathrm{C}}$, where $\mathrm{P}_{\mathrm{A}}, \mathrm{P}_{\mathrm{C}}, \mathrm{P}_{\mathrm{B}}-$ oils, asphaltenes and resins content in the analyzed sample, respectively, mass $\% ; \mathrm{A}_{0}-$ the initial value of the projection of the sample magnetization; $\mathrm{A}_{1}$ and $\mathrm{A}_{2}$ - the values of amplitude of the transverse magnetization, determined at sample temperature of $40{ }^{\circ} \mathrm{C}$ and $100{ }^{\circ} \mathrm{C}$, respectively. Three samples were studied: sample 1 pure bitumen BN 90/10; sample 2 - BPB (BN 90/10 + $3 \%$ Oil-Polymer resins - OPR, 6\% rapeseed oil); sample 3 - BPB (BN 90/10 + $3 \%$ OPR, $7 \%$ rapeseed oil). The components were mixed for 15-20 minutes at $100-120^{\circ} \mathrm{C}$. The results are shown in Table 1.

Table 1. Chemical composition of the BPB

\begin{tabular}{cccc}
\hline Sample, No. & Oils (saturates) & Resins & Asphaltenes \\
\hline 1 & 8.14 & 31.76 & 60.1 \\
2 & 18.32 & 33.65 & 48.03 \\
3 & 20.01 & 33.71 & 46.28 \\
\hline
\end{tabular}

The optimal composition of plasticizer for BPB is determined (70\% wt. OPR $+30 \% \mathrm{wt}$. rapeseed oil).

\section{Summary}

It has shown that the injection of the polymer additive the amount of oil fraction increases, the amount of 
asphaltenes decreases, bitumen dilution happens, solvation shell partially immerse into oil fraction. Thus, it was shown that the polymer is interacts to a greater extent with a part of the oil fraction of bitumen (lighter), dissolving therein and thus the polymeric additive increases in percentage of bitumen oil fraction that has been given above using Hildebrant index, which is by its numerical value practically the same as that of the polymer and of the aromatic maltenes that are included in the oil fraction of the bitumen.

During the comprehensive solution of the scientific applied tasks aimed at developing scientific bases and creating new bitumen-polymer materials recipes and production techniques (GOST 30547-97 "Materials rolled roofing and waterproofing", GOST 30693-2000 "Mastic roofing and waterproofing") based on domestic produced TPR, using a solvent such as plasticizer SDO in the present studies several important and urgent problems of the national economy were solved:

1. Using the method of pulsed NMR the regularities of the impact of modifier component composition on the changes of structural-group composition of the original and modified products were specified;

2. Based on the results of research the optimal ratio of BPB components was investigated, the manufacturability of the process for obtaining of composite bituminous materials for civil engineering with the aim of optimizing the quality of the final products was evaluated.

3. The technological option of the higher developed compositions of roofing waterproofing materials, using pulsed NMR - spectroscopy as input and output quality control of bituminous products was developed.

4. On the basis of pulsed NMR data the regularities of redistribution of the phases $\mathrm{P}_{\mathrm{A}}, \mathrm{P}_{\mathrm{B}}, \mathrm{P}_{\mathrm{C}}$ with different molecular mobility and their relationship with the binder components were investigated. Rapid technique for quantifying the content of polymer in the solvent was developed.

Despite the many advantages (such as non-destructive nature of research), NMR does not provide the data on the chemical composition. In connection with this - in the long term research to develop rapid methods to study the composition of bitumen-polymer systems using NMR spectroscopy in combination with other physical and chemical methods of analysis.

\section{Acknowledgement}

The work is performed according to the Russian Government Program of Competitive Growth of Kazan Federal University

\section{References}

Bayer, J., Jaeger, F., \& Schaumann, G. E. (2010). Proton nuclear magnetic resonance (NMR) relaxometry in soil science applications. The Open Magnetic Resonance Journal, 3, 15-26. http://dx.doi.org/1874-7698/10

Berman, P., Levi, O., Parmet, Y., Saunders, M., \& Wiesman, Z. (2013). Laplace Inversion of Low-Resolution NMR Relaxometry Data Using Sparse Representation. Concepts in Magnetic Resonance. Part A, Bridging Education and Research, 42(3), 72-88. http://dx.doi.org/10.1002/cmr.a

Charlier, C., Khan, S. N., Marquardsen, T., Pelupessy, P., Reiss, V., Sakellariou, D., ... \& Ferrage, F. (2013). Nanosecond Time Scale Motions in Proteins Revealed by High-Resolution NMR Relaxometry. Journal of American Chemical Society, 135, 18665-18672. http://dx.doi.org/10.1021/ja409820g.

Conte, P., \& Alonzo, G. (2013). Environmental NMR: Fast-field-cycling Relaxometry. eMagRes, 2, $389-398$. http://dx.doi.org/10.1002/9780470034590.emrstm1330

Frantsuzov, I. (2010). An NMR Relaxometry Study of Heteronuclear Effects Upon Proton Transfer in Hydrogen Bonds. Thesis for the degree of Doctor of Philosophy, the University of Nottingham, the United Kingdom.

Haber-Pohlmeier, S., Stapf, S., Dusschoten, D., \& Pohlmeier, A. (2013). Relaxation in a Natural Soil: Comparison of Relaxometric Imaging, T1-T2 Correlation and Fast-Field Cycling NMR. The Open Magnetic Resonance Journal, 3, 57-62. http://dx.doi.org/1874-7698/10

Kemalov, A. F., \& Kemalov, R. A. (2013). Structural and Dynamic Studies of Naphtha Crude Residue with Different Chemical Nature. World Applied Sciences Journal (Special Issue on Techniques and Technologies), 22, 16-22. http://dx.doi.org/10.5829/idosi.wasj.2013.22.tt.22147

Kemalov, A. F., Kemalov, R. A., \& Valiev, D. Z. (2013). Study of the structure of complex structural units of heavy oil from Zyuzeevskaya field by NMR relaxometry and rheological studies. Oil Industry, 2, 63-65. ISSN: 00282448

Kemalov, R. A., Kemalov, A. F., \& Valiev, D. Z. (2012). Thermodynamics of viscous flow activation and structural-dynamic analysis of high-viscosity oil with ultrasonication. Oil industry, 12, 100-103. 
Kimmich, R., \& Anoardo, E. (2004). Field-cycling NMR relaxometry. Progress in Nuclear Magnetic Resonance Spectroscopy, 44, 257-320. http://dx.doi.org/10.1016/j.pnmrs.2004.03.002

Kruk, D., Herrmann, A., \& Rössler, E. A. (2012). Field-cycling NMR relaxometry of viscous liquids and polymers. Progress in Nuclear Magnetic Resonance Spectroscopy, 63, 33-64. http://dx.doi.org/10.1016/j.pnmrs.2011.08.001

Nascimento, A. M. R., Tavares, M. I. B., \& Miguez, E. (2004). Evaluation of Sorva Latex by 1H NMR Relaxometry. Annals of magnetic resonance, 3(3), 82-86. Retrieved from http://www.auremn.org.br/Annals/2004-vol3-num3/2004-3-82-86.pdf

Twieg, M. (2013). Open source NMR relaxometry platform. Unpublished dissertation in partial fulfillment of the requirements for the degree of Master of Science, Case Western Reserve University, Cleveland, USA.

Washburn, K. E., \& Birdwell, J. E. (2013). Enhanced Laboratory Methods for Shale Analysis using Low Field NMR Relaxometry. Abstract archive of the Geoconvention-2013: Integration. Retrieved from http://geoconvention.org/archives/2013abstracts/214_GC2013_Enhanced_Laboratory_Methods.pdf

Xu, F., Leclerc, S., \& Canet, D. (2013). NMR relaxometry study of the interaction of water with a nafion membrane under acid, sodium, and potassium forms. Evidence of two types of bound water. The journal of physical chemistry B, 117(21), 6534-6540. http://dx.doi.org/10.1021/jp311062h

\section{Copyrights}

Copyright for this article is retained by the author(s), with first publication rights granted to the journal.

This is an open-access article distributed under the terms and conditions of the Creative Commons Attribution license (http://creativecommons.org/licenses/by/3.0/). 